and equipment is being built up and the staff strengthened. Sand deposits have been surveyed both for their economic value and also to collect information for shoreline research. The detailed survey so far has covered much of the east coast of Northland, where the modern shore and off-shore flats eontain between 50 per cent and 75 per cent of lime soda feldspar. Clay deposits near Coalgate and Hororata in Canterbury, examined by the Geological Survey and Chemistry Division, contained an excellent grade of bentonite. A new series of geological maps of the main cities is being prepared and the Seismological Observatory is investigating the mechanisms of earthquakes, including theoretical research on alternative mechanisms which could cause a sudden change in the conditions of elastic equilibrium within the Earth. Earthquake occurrence has been subjected to statistical analysis, with respect both to position and to time, and members of the Applied Mathematics Division co-operating with the Geophysics Division are making a statistical analysis of the patterns of occurrence and location of earthquakes.

The Physics and Engineering Laboratory is developing a method of presenting information on the radiation output from various types of heaters for guidance in calculating the effect of the radiation on the comfort of people, by engineers and architects. The Chemistry Division has also developed automatic apparatus for separating the two types of silver and cupro-nickel coins in circulation in view of the change-over to decimal currency.

A detailed analysis of results obtained from the Bluff radar during the International Geophysical Year revealed a number of new and unsuspected features in the pattern of behaviour of the radar aurora and gave the first clues as to the over-all pattern. Increases in ground radioactivity from nuclear weapons tests continue to be studied, while the principle of the electromagnetic flowmeter has been applied to the measurement of blood flow in the heart lung machines of the cardio-thoracic surgical unit at Green Lane Hospital and also for measuring fluid flow in the artificial kidney.
Soil studies by the Grassland Division have shown that organic phosphorus may progressively accumulate under permanent pastures forming about 60 per cent of the total phosphorus in such soils. A survey of the vegetation and soils of the Tongariro National Park, initiated in 1960, is now nearing completion. A new variety of oats named 'Mapua', bred at the Cross Research Division, was selected from a 1953 cross of 'Milford', a lodgingresistant Welsh variety, and 'Onward', a plump-grained English oat. In full-scale trials since 1957-58 it was superior to all present varieties, highly resistant to lodging and of reasonably good milling quality. Since 1962 the Division has also produced three promising hybrid varieties of onion for field trials, and commercial release of New Zealand Hybrid No. 1 has already been requested. From crosses of turnips with aphid- and mosaic-resistant swedes, turnips have been selected with high field tolerance to these diseases. The work of the Plant Diseases Division on heat therapy for the control of post-harvest fruit rot has concentrated on hot-water treatment for pip fruits and peaches. With apples and pears Botrytis rots were not controlled at temperatures tolerable to the fruits, but the method would appear to have applications in the control of stone fruit brown rot in peaches, especially canning peaches. The new compound zeatin, extracted from the sweet corn kernels, has now been shown to be 6-(4-hydroxy-3-methylbut-2-enyl) amino-purine.

As a preliminary to detailed study of the movement of behaviour of red deer and other animals, the Animal Ecology Division is developing techniques for capture and marking. The Tobaceo Research Station has undertaken a programme of breeding for resistance to Verticillium wilt black root rot, Phytophthora and mosaic virus.

Included with the Director-General's report are reports from the branches and from the incorporated research associations. The seventh annual report of the Ross Dependency Research Committee is appended. Lists of publications are included in the reports from the various branches.

\title{
FOREST HYDROLOGY
}

\begin{abstract}
$A^{N}$ Advanced Science Seminar supported by the U.S. A National Science Foundation was held at the Pennsylvania State University, State College, during August 29-September 10. The symposium was conducted by the School of Forestry with three other bodies: the Northeastern Forest Experimental Station, United States Forest Service; the International Association of Scientific Hydrology; and the International Union of Forest Research Organizations. Twenty-one countries were represented at the symposium by eighty-five participants, the largest single group being from the United States. Eighty-five papers and reports were delivered and the proceedings will be published during the next nine months. Sound organization and critical discussion stimulated by several invited scientists made this a successful meeting.

Many countries are concerned about the adequacy of existing and future water resources, and in most, research is being conducted into these and other problems in hydrology. Particular attention has been given to investigating the hydrological significance of different types of land use and, during the past $30-40$ years, the hydrological role of forests has been studied in various parts of the world. Some well-known experiments have been conducted, particularly in the United States, Switzerland and South Africa, but investigations commenced more recently have had the benefit of modern instrumentation and better techniques from the start. The aim of these experiments is to compare the water balance of forest
\end{abstract}

catchments with adjoining catchments of a different vegetational character by showing differences in the volume and distribution of run-off. Now, energy budgets for catchments are being drawn up in addition to water balances and, with the use of neutron scatter devices for soil moisture measurement, considerable advances are being made in the study of forest hydrology. The importance of research of this type and also the timely nature of the symposium were emphasized by the severe water shortage in New York City and surrounding areas during August-September.

The symposium commenced with a review of activities in each country represented. In Israel, a country of few trees, difficulties arise from lack of water, in contrast to Taiwan with too much water and many trees. This distinction between countries where water conservation is important and those with the problem of soil conservation was most apparent. In many countries there seemed to be an unnecessary division of responsibility for hydrological research among a number of different organizations.

The second session considered forests and precipitation - the forest being regarded as a redistributor rather than a stimulator if occult precipitation was not taken into account. The problems involved in assessing precipitation over a catchment were described by Corbett (U.S.A.) using material from San Dimas Watershed. Leonard (U.S.A.) was concerned with the mathematies of inter- 
ception, while Leyton, Reynolds and Thompson (Great Britain) showed that the reduction of transpiration from wetted leaves was exceoded by the accompanying increase in evaporation. Through-fall, stem-flow and interception in different stands as related to gross precipitation were given attention with the distribution of moisture in forest soils. Such matters as surface detention and drip studies, canopy cover measures and through-fall drop sizes were touched on by Zinke in a thorough review of interception investigations carried out in the United States. Snow in forests was considered in relation to transport processes and the mechanics of interception, and Martinelli (U.S.A.) gave an account of methods of increasing high altitude snow packs.

In the session on forests and soil water, the difficulties involved in defining and separating components of the hydrograph were evident in papers dealing with overland flow and sub-surface flow. Hewlett (U.S.A.) devised a response factor for classifying the hydrological performance of drainage basins in Appalachian forest areas, while Zahner (U.S.A.) dealt with estimation of moisture régimes for three forest soils, by using a balance between rainfall and potential evapotranspiration with the appropriate soil moisture release curve. Field determinations of moisture régimes beneath different vegetation types were described by Shachori (Israel), who showed that a greater reduction in moisture content was caused by maquis than by pine or pasture. There were five papers on various aspects of forest management and yield as related to soil moisture and ground water. In two of these, rise in the water table after thinning of pine and birch stands to various densities was reported, first by HolstenerJørgensen (Denmark) for a clay area and then by Heikurainen (Finland) for peat.

Penman (Great Britain) started the session on forests and evapotranspiration by comparing theoretical evaporation from forests with observed results. Records from the Castricum lysimeters and two East African forest catchments were used to indicate how calculated evaporation values approached the difference between rainfall and run-off. Baumgartner (Germany) showed energy reasons for differing evapotranspiration rates over various types of surface, and he demonstrated that the onergy available for evaporation at a grass surface was only three quarters of that for a forest. A six-year investigation of the evaporation from a Scots pine stand in south-east England was described by Rutter, and the result $\left(E_{T}=1 \cdot 20 E_{0}\right)$ was accounted for in terms of the increase in evaporation of intercepted water over the reduction in transpiration. Knoerr (U.S.A.) solved the energy balance equation for a single leaf for different temperatures, humidities and stomatal resistances, and Swanson (U.S.A.) gave an example of the use of the heatpulse velocity method of sap flow measurement in his investigation of transpiration from pine and spruce. The value of the dual approach on water balance and energy budget lines was apparent from Pereira's account of land use hydrology experiments conducted in East Africa. Various aspects of the relation between evapotranspiration and forest management (including the use of antitranspirants) were dealt with in several papers. In one, Waggoner (U.S.A.) reported that chemical sprays used to close stomata caused a 20 per cent roduction in transpiration from single trees, but that a method of treating whole forests had to be found before a significant increase in run-off and water yield could be achieved.

In the 'Forests and Run-off' session, Lull and Sopper (U.S.A.) used records of discharge from a large number of small catchments in the north-east United States, with topographic and other characteristics of those catchments, in a series of multiple regression analyses to evolve a method of predicting various parameters of run-off. Ogihara (Japan) was concerned with predicting flood discharges from forest catchments, and, by using a nonlinear relationship which included a measure of catch- ment wetness and rainfall, he was able to show the effect of forest cutting on floods. Differences in the volume and distribution of run-off from cleared north and south facing eatchments at Coweeta were mentioned by Hibbert (U.S.A.), and later it was suggested that these differences might be linked to the small size of the cleared areas, making them unrepresentative. A second Japanese paper (Nakano) dealt with clearing forest catchments and showed that the effect of cutting in increasing flow is statistically significant at the 5 per cent level only for the first few years.

Several papers in the session on forests and soil stabilization dealt with the factors controlling erosion, such as rainfall characteristics, topography and litter cover. The quantitative measurement of erosion was discussed and the use of Middleton's dispersion ratio and Anderson's surface aggregate ratio mentioned. Margaropoulos showed how small dams and woven barriers with contour planting had been used to control erosion in Greece and the potential of high altitude sites in Austria for re-establishment of forest was reported by Aulitzky. In this paper it was reported that measurements of solar radiation had been made in excess of the solar constant by 18 per cent for periods of 10-20 min. Vegetational control of erosion. in loess areas and strip mined areas of the U.S.A. was described along with New Zealand investigations of erosion.

Errors in run-off measurement, calibration methods for catchments and data processing of stream-flow were subjects discussed in the first papers in the instrumentation and techniques session. Anderson (U.S.A.) reported on new techniques in multivariate analysis applied to determining sediment yield. Wicht discussed the validity of the South African catchment experiments, but doubted that a method of analysis had been evolved which could readily show the effects of burning, eutting or the development of forest cover. Papers on digital hydrological synthesis and the use of isotopes concluded the session.

A panel discussed a variety of new instruments including several neutron scatter devices, a pressure pillow for snow measurement, snow depth markers that can be read from the air, a photo-electric device for measuring snow in the air, a snow resistograph, and an economical radiometer fitted with a mercury current integrator. A display of these and other instruments took place at the end of the symposium.

Films of a number of experimontal areas in North America were shown, including one giving vivid portrayal of the fire at the San Dimas Watershed. Several experimental sites were visited, including a flood-prevention project and a waste-water renovation project. In this latter experiment, treated sowage effluent was being sprayed over croplands and over a forest area and there had been considerable increases in yield and growth, as well as appreciable ground water recharge.

From the papers and discussions it was apparent that a considerable effort had already gone into forest hydrology. In this context it is perhaps surprising that for a country with a rapidly accelerating demand for water, Britain has had such a limited research programme for evaluating relationships between the hydrology and land use of catchment areas. Although some worth-while investigations of forest hydrology have been carried out, not one has been on a catchment scale and has involved a land use change. Several experiments of this type are proposed in the programmo of the Hydrological Research Unit, Natural Environment Research Council, but owing to administrative difficulties they have not yet been started. These experiments should considerably assist the understanding of the hydrological cycle in a forest environment, as they will incorporate recently developed. methods of automatic data collection and analysis. It is hopod that these new methods will help in overcoming the handicap of Britain's late start in forest hydrology.

JOHN C. RODDA 